\title{
Vertical safe separation distance between openings in multi-storey buildings having a fire resistant spandrel
}

\author{
Michael A Delichatsios, Joe Ryan, Ning Tian and Jianping Zhang \\ Fire Safety Engineering Research and Technology Centre, University of Ulster, UK
}

\begin{abstract}
A novel comprehensive methodology is presented for the determination of the vertical separation distance between floor glazing openings in buildings having a fire resistant non-flammable spandrel. The spandrel height is specified by requiring that the heat flux is less than a critical heat flux for glazing failure at the base of the opening of the floor above the floor of fire origin. For a specified room, opening geometries and fuel type, the heat flux at the base of this opening is calculated by using correlations for the flame height and heat flux distribution of the façade flames for under ventilated fire conditions in the compartment of fire origin. As the compartment opening increases a transition occurs from under ventilated to over ventilated conditions reducing the façade fire spread hazard. The methodology and results can also be applied for wooden and lightweight façade walls to predict fire spread behavior on the wall and towards the openings to floors above the floor of fire origin.
\end{abstract}

\section{INTRODUCTION}

The main mechanisms of façade flame spread after an initiating fire at the floor of fire origin are summarized as:

- Fire spread to the interior of level above via openings such as windows causing secondary interior fires on levels above resulting in level to level fire spread.

- Flame spread over the external surface of the wall.

- Flame spread within an interval vertical cavity /air gap.

- Heat flux impacts cause degradation/separation of non-combustible external skin resulting on flame spread on internal core.

- Secondary external fires to lower (ground) levels arising from falling burning debris.

In this work we examine flame spread from floor to floor through glazing openings when the spandrel is fire resistant. Radiant heat to adjacent buildings, combustibility of external wall claddings and firestopping internally between floors are dealt with in great detail in fire safety codes in the British Isles as well as internationally. The possibility of fire spread externally from floor to floor is generally not considered in detail 


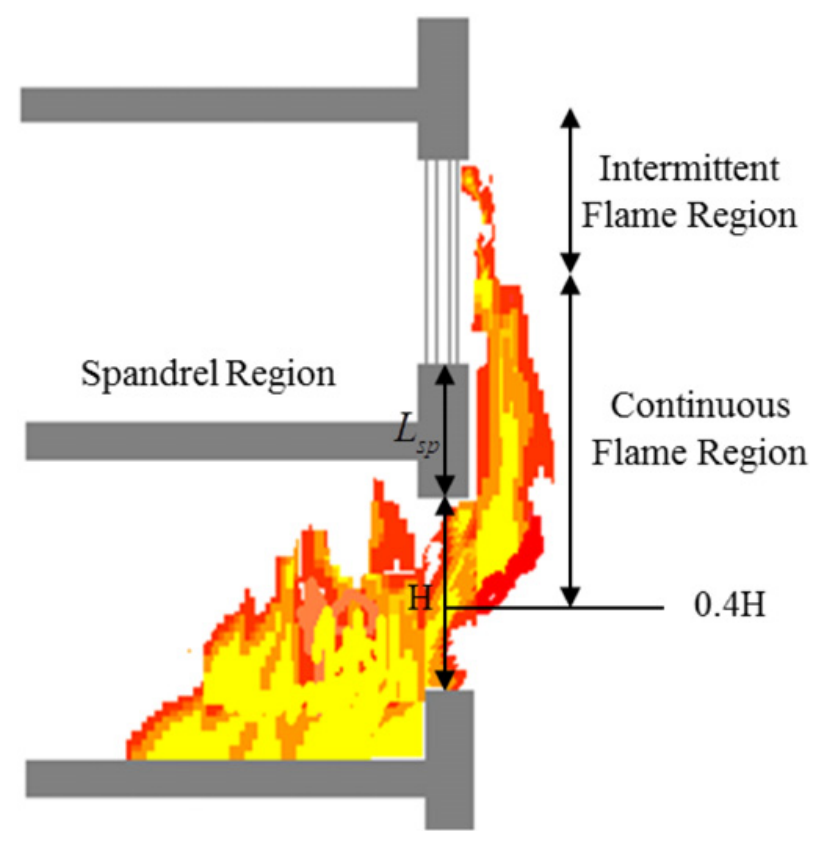

Figure 1. Floor to Floor External Fire Spread.

In under-ventilated fires the unburned fuel will flow out and burn at the exterior of the building after the window in the enclosure breaks. Because the unburned fuel has been sufficiently heated and ignited, it is possible to have external flame heights with associated heat flux levels applied on the floor above the floor of fire origin, which could cause fire spread between floors through windows. This is also possible for well-ventilated fires, but as the fuel has enough air to burn inside the compartment exterior flames would be much smaller. We demonstrate in this work that considerable flame height and heat flux values can be reached when specific opening sizes are associated with specific room sizes and fuel loads, which could lead to fire breakthrough on the floor above the floor of fire origin through windows even for the case that fire resistant standard block or concrete construction is used for the outside wall.

Currently, there are no test methods for assessing fire resistance of wall systems in UK in any of the jurisdictions. There is also no specification or guideline in the UK for required external vertical separation distance between floors with regard to the threat of external fire spread. The general view taken is that once fire-stopping is brought to the external weather line of the building, then external fire spread is not an issue. American codes require protection between floor openings where buildings are more than three stories high not sprinklered Specifically, e.g. NFPA 5000 37.1.4 requires a fire resistant spandrel when openings in the floor above are within $1.5 \mathrm{~m}$ of the floor below. In addition, the Taiwanese building regulations require a spandrel separation distance of greater than $0.90 \mathrm{~m}$ between floor openings. There is also an ASTM test standard E2307 for determining the fire resistance of perimeter fire barrier systems i.e. the joint between an exterior wall assembly and a floor system. The test method determines the ability of wall systems to prevent fire spread as they deflect and deform under intensive heat.

In this work we consider that the area between floor openings is fire resistant, as it would be in standard block or concrete construction by emphasizing that fire spread from a floor to the floor above will occur due to glazing failure and not because of failure of a spandrel region of a curtain wall system.

Figure 1 illustrates how fire spread from floor to floor occurs. The extent of the spandrel is defined as the length from the top of the opening in the room of fire origin to the bottom of the opening in the 
next floor as Fig. 1 indicates. The worst condition for fire spread from floor to floor develops when fires in the floor of fire origin are under-ventilated. In a well-ventilated fire scenario all, or nearly all, of the fuel is burned inside the compartment of fire origin so that any heat fluxes from short exterior elongated flames are not as high as in under-ventilated fires.

In under-ventilated fires unburned fuel escapes from the compartment ignited and burning outside the compartment generating a façade flame as in Fig. 1. If there is sufficient unburned fuel outside the compartment this will burn with ambient air and can cause fire breakthrough from the floor of fire origin to the floor level above. The focus of this work is to calculate the amount of unburned fuel that could be created in a given situation and to establish the parameters for which this could cause fire breakthrough and spread through the upper floor openings. We are primarily interested in the vertical separation distance required between floors in a given situation. There are a number of factors that will affect this, including: Room size, Room Type, Window Opening Area, Window Opening Dimensions, Room/Store Height, and Window Opening Location.

We focus in this work on window opening size, compartment dimensions and fuel load. We first describe the methodology to find out the specific range of the opening size in relation to the room size to generate façade flames that can cause fire breakthrough. Then we show that breakthrough occurs when the opening dimensions have certain relations to the fuel load available (for given room size and type) in order to produce external flame heights and heat fluxes.

\section{THEORY AND METHODOLOGY (UNDER-VENTILATED FIRES)}

The theory and methodology is based on the extensive work done in FireSERT and SKLFS China for enclosure and façade fires [1-6]. In reference [6] a review of previous works on façade fires are included.

The results from [1-5] used in this paper are next summarized for under-ventilated fires:

1. The air inflow for the opening:

$$
\dot{m}_{a}=0.5 A H^{0.5}(\mathrm{~kg} / \mathrm{s})
$$

Here $A=$ area of opening $\left(\mathrm{m}^{2}\right), H=$ height of the opening (m) and the Coefficient 0.5 has a dimensional value $\mathrm{kg} / \mathrm{s} \cdot \mathrm{m}^{5 / 2}$.

2. The total mass pyrolysis rate inside the enclosure:

$$
\dot{m}_{T}=0.1 A H^{0.5}=0.2 \dot{m}_{a}(\mathrm{~kg} / \mathrm{s})
$$

3. The fuel burned inside the enclosure is at stoichiometric proportions to the incoming air, $S$ is air to fuel mass stoichiometric ratio:

$$
\dot{m}_{i n s}=\frac{\dot{m}_{a}}{S}(\mathrm{~kg} / \mathrm{s})
$$

4. It follows that the excess mass pyrolysate rate burning outside on the façade is :

$$
\dot{m}_{e x t}=\dot{m}_{T}-\frac{\dot{m}_{a}}{S}=\dot{m}_{a}\left(0.2-\frac{1}{S}\right)
$$

and the heat released externally on the façade is

$$
\dot{Q}_{e x t}=\dot{m}_{e x t} \Delta H_{C}=\dot{m}_{a}\left(0.2-\frac{1}{S}\right) \Delta H_{C}=\left(\dot{m}_{T}-\frac{\dot{m}_{a}}{S}\right) \Delta H_{C}
$$

where $\Delta H_{C}$ is the het of combustion of the fuel. 


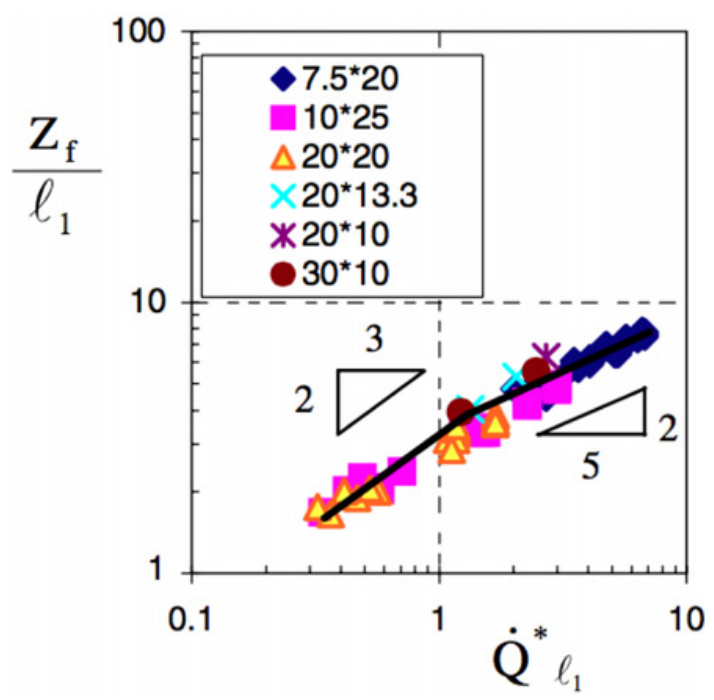

Figure 2. Flame height correlation with normalized external heat release rate.

5. Figure 2 shows the relation for the façade flame heights to the normalized external heat release rate.

The flame height generated by the external heat release rate is:

$$
\begin{aligned}
& Z_{f}=3.2 \dot{Q}_{\ell 1}^{*^{2 / 3}} \text { for } \dot{Q}^{*}<1.3 \\
& Z_{f}=3.2 \dot{Q}_{\ell_{1}}^{*^{2 / 5}} \text { for } \dot{Q}^{*}>1.3
\end{aligned}
$$

where the length scale $\ell_{1}=\left(A H^{0.5}\right)^{2 / 5}$ and the normalized heat release rate is defined as :

$$
\dot{Q}_{\ell_{1}}^{*}=\frac{\dot{Q}_{\text {ext }}}{\rho_{\infty} c_{p} T_{\infty} \sqrt{g} \ell_{1}^{5 / 2}}=\frac{\Delta H_{C}}{c_{p} T_{\infty}}\left(\frac{0.5}{\sqrt{g} \rho_{\infty}}\right)\left(0.2-\frac{1}{S}\right)
$$

Equation (6c) has been derived by using Eqs. ((1)-(5)).

where

$c_{p}$ is specific heat capacity of air equal to $1 \mathrm{~kJ} / \mathrm{kg} \mathrm{K}$.

$T_{\infty}$ is ambient air temperature (K) equal to $293 \mathrm{~K}$.

$g$ is acceleration due to gravity equal to $9.81 \mathrm{~m} / \mathrm{s}^{2}$.

$\rho_{\infty}$ is ambient air density equal to $1.2 \mathrm{~kg} / \mathrm{m}^{3}$.

$S$ is stoichiometric air-fuel mass ratio.

We note that the normalized external heat release rate in Eq. (6c) is independent of the opening or room geometry. Moreover, the origin of the flame height is located at $0.4 \mathrm{H}$, which corresponds to the neutral plane for the flow at the opening. For enclosure under-ventilated fires the normalized heat release rate is less than one so that Eq. (6a) applies.

6. The normalized heat flux distribution along the façade wall for the external flames is shown in Fig. 3.

For subsequent use, we make the following observations regarding the heat flux to the façade wall:

a. The continuous flame height is at $0.8 Z_{f}$ of the mean flame height $\left(Z_{f}\right)$.

b. The heat flux over the continuous flame height (regime I) takes a maximum constant value given by the following equation after using Eq. (6a): 
$2^{\text {nd }}$ International Seminar for Fire Safety of Facades, Lund (Sweden), 2016

$$
\frac{\dot{\mathrm{q}}_{\mathrm{t}}^{\prime \prime} \mathrm{Z}_{\mathrm{f}} \mathrm{e}^{0.6\left(\mathrm{H} / \ell_{1}\right)}}{\dot{\mathrm{Q}}_{\mathrm{ext}} / \ell_{1}}
$$

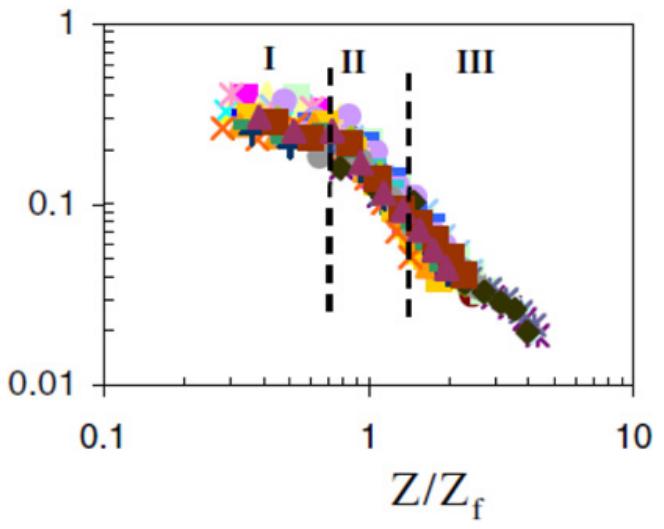

Figure 3. Normalized heat flux distribution along the façade against vertical location normalized by the flame height. The origin of the flame height is at $0.4 \mathrm{H}$ and there regimes of the heat flux distribution are shown, continuous (I), intermittent (II) and thermal (III).

$$
q_{\mathrm{t}, \text { max }}^{\prime \prime}=0.35 \frac{\dot{\mathrm{Q}}_{\mathrm{ext}}}{Z_{f} \mathrm{e}^{0.6\left(\frac{\mathrm{H}}{I_{1}}\right)} \ell_{1}}=0.35 \frac{\dot{\mathrm{Q}}_{\ell_{1}}^{* 1 / 3} \rho_{\infty} \mathrm{c}_{\mathrm{p}} \mathrm{T}_{\infty} \sqrt{g} \ell_{1}^{1 / 2}}{3.2 \mathrm{e}^{0.6\left(\frac{\mathrm{H}}{\mathrm{I}_{1}}\right)}}=0.1 \frac{\dot{\mathrm{Q}}_{\ell_{1}}^{* 1 / 3} \rho_{\infty} \mathrm{c}_{\mathrm{p}} \mathrm{T}_{\infty} \sqrt{g} \ell_{1}^{1 / 2}}{\mathrm{e}^{0.6\left(\frac{\mathrm{H}}{\ell_{1}}\right)}}
$$

c. The continuous flame regime is followed by the intermittent regime II and then the buoyant thermal flow regime III above the flame extent. The heat flux distribution over the first two regimes is given as

$$
\begin{aligned}
q_{t}^{\prime \prime} & =q_{t, \text { max }}^{\prime \prime} \text { for } Z<0.8 Z_{f} \\
\frac{\dot{q}_{t}^{\prime \prime}}{\dot{q}_{t, \text { max }}^{\prime \prime}} & =0.64\left(\frac{Z}{Z_{f}}\right)^{-2} \text { for } Z>0.8 Z_{f} .
\end{aligned}
$$

\section{DETERMINATION OF A SAFE SPANDREL HEIGHT}

Flame spread from the façade flames to the floor above the floor of fire origin through its window will not occur if the heat flux at the bottom of this window is less than a critical heat flux for glass breakage, $\dot{q}_{\mathrm{cr}}^{\prime \prime}$, which depends on the glazing system. The location of the bottom of the window from the origin of the flames is:

$$
Z_{s p}=0.6 H+L_{s p}
$$

where $L_{s p}$ is the length of the spandrel section (see Fig. 1).

If the critical heat flux is less or equal to the maximum flame heat flux (Eq. (7)) the required spandrel length for no flame spread is given by:

$$
\frac{Z_{s p}\left(=0.6 H+L_{s p}\right)}{Z_{f}}=0.8\left(\frac{\dot{q}_{t, \max }^{\prime \prime}}{\dot{q}_{c r}^{\prime \prime}}\right)^{1 / 2} \text { if } \dot{q}_{c r}^{\prime \prime} \leq \dot{q}_{t, \max }^{\prime \prime} .
$$


If the critical heat flux is greater than the maximum heat flux

$$
\dot{q}_{c r}^{\prime \prime}>\dot{q}_{t, \text { max }}^{\prime \prime} \text { there is no restriction on the spandrel height }
$$

so that the minimum height can be chosen based only on construction requirements.

We note that the maximum heat flux for the façade flames in Eq. (7) depends primarily on the geometry of the opening namely the length scale $l_{1}=\left(A H^{0.5}\right)^{2 / 5}$ and the ratio $H / l_{1}$. It follows that the condition $\dot{q}_{c r}^{\prime \prime}=\dot{q}_{t, \text { max }}^{\prime \prime}$ can be satisfied for certain geometric characteristics of the opening.

\section{CROSSOVER FROM UNDERVENTILATED TO OVERVENTILATED CONDITIONS AS OPENING SIZE INCREASES}

Simple inspection for the flame height Eq. (6) and heat flux relations Eqs. (7) and (8) shows that the conditions for spandrel separation heights become more restrictive as the opening factor $\left(A H^{0.5}\right)$ or equivalently the length scale $\left(l_{1}=\left(A H^{0.5}\right)^{2 / 5}\right)$ increase. As the opening dimensions increase more air flows into the compartment leading to the change of conditions from under-ventilated to over-ventilated. This cross over occurs when the total mass pyrolysis rate becomes less than the stoichiometric air requirements [1-5]:

$$
\dot{m}_{T}<\frac{\dot{m}_{a}}{S}=\frac{0.5 A H^{1 / 2}}{S} .
$$

The maximum mass pyrolysis for over ventilated conditions in an enclosure is equal to mass pyrolysis rate per unit area multiplied by the effective fuel area $\dot{m}_{T}=\dot{m}_{F}^{\prime \prime} \cdot A_{F}$ so that Eq. (10a) provides the minimum opening factor above which over ventilated conditions prevail:

$$
\begin{gathered}
A H^{1 / 2}=\ell_{1}^{5 / 2} \geq 2 S \cdot \dot{m}_{F}^{\prime \prime} \cdot A_{F} \\
\ell_{1} \geq\left(2 S \cdot \dot{m}_{F}^{\prime \prime} \cdot A_{F}\right)^{2 / 5} .
\end{gathered}
$$

As the conditions are over-ventilated when Eq. (10) is satisfied all combustion occurs nearly inside the enclosure and the conditions are much less critical than when conditions were just under-ventilated.

\section{ILLUSTRATION OF THE METHODOLOGY USING EQUATIONS (1)-(10)}

We apply the methodology for determining spandrel height separation for a typical office and a typical shop as shown in Figs. 4 and 5. In both cases the floor area is $4 \mathrm{~m}$ by $5 \mathrm{~m}$. The heat of combustion and stoichiometric ratio for the office is $\Delta H_{C}=19000 \mathrm{~kJ} / \mathrm{kg}$ and $S=6.3$ whereas the corresponding values for the office are $\Delta H_{C}=22500 \mathrm{~kJ} / \mathrm{Kg}$ and $S=7.4$. These values represent an average fuel being primarily paper for office and primarily polymer such as PMMA for the shop. In Fig. 4 we keep the opening width fixed for the office at $1 \mathrm{~m}$ and vary the opening height. In Fig. 5 we keep the opening height fixed and vary the opening width. Figures 4 and 5 plot the variation of the maximum heat flux (Eq. (7)) and the continuous flame height $\left(0.8 Z_{f}\right.$ from Eq. (6a)) as the opening height and width changes respectively.

In addition, Figs. 4 and 5 include two critical heat fluxes as horizontal lines corresponding to failure of the glazing. In our analysis, we will use the values, $70 \mathrm{~kW} / \mathrm{m}^{2}$ and $20 \mathrm{~kW} / \mathrm{m}^{2}$ [13], as our cut-off points for fire breakthrough for tempered and non-tempered glass. While this is an obvious simplification, and 
$2^{\text {nd }}$ International Seminar for Fire Safety of Facades, Lund (Sweden), 2016

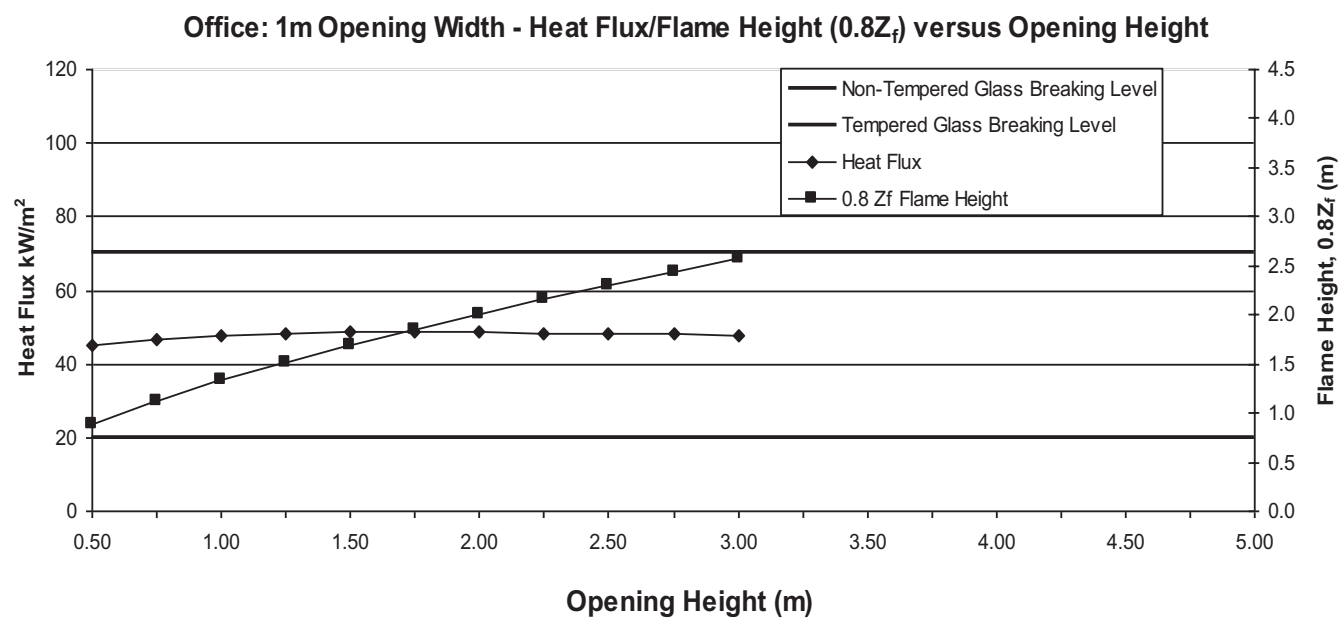

Figure 4. Office: maximum heat flux and continuous flame height calculations.

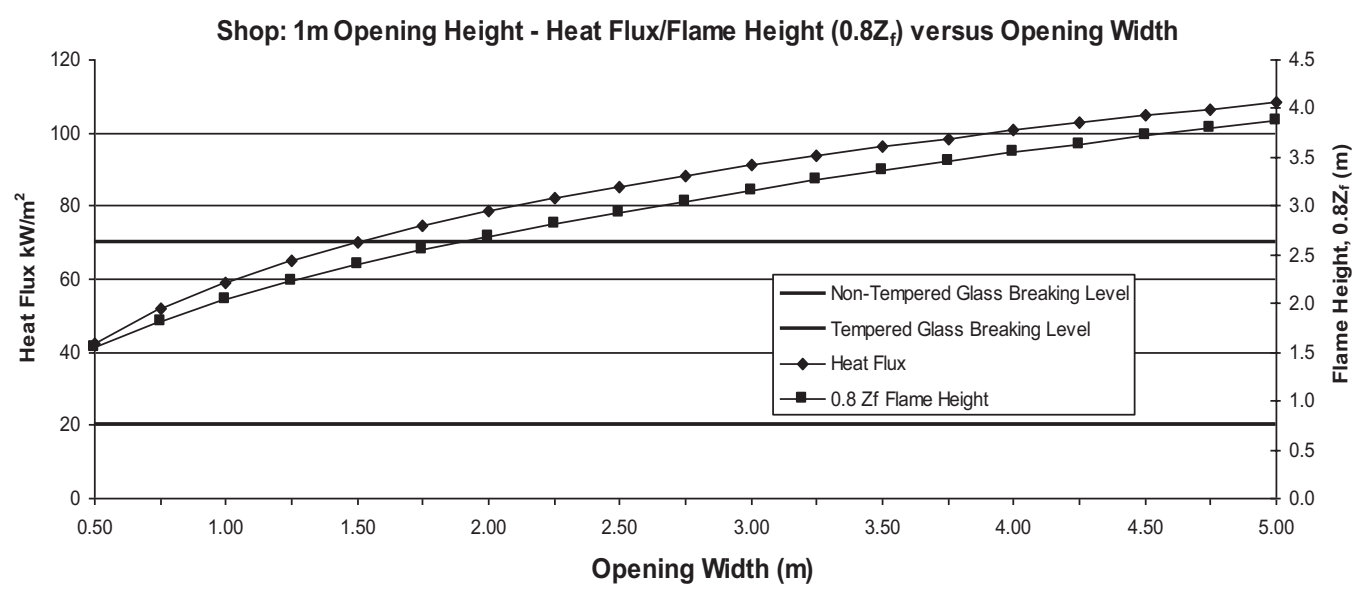

Figure 5. Shop: maximum heat Flux and continuous flame height calculations.

various different studies have given a range of different values for all types of glazing, these values still give us a good general indication for analysis purposes.

Finally, we note in Figs. 4 and 5 that calculations stop at certain height for office (Fig. 4 for office) and a certain width for shop (Fig. 5 for shop) at which point conditions change from under-ventilated to over-ventilated as the opening factor takes an appropriate value. The crossover condition provides the length scale $\ell_{1}$ as given by Eq. (10) where we have used the value $\dot{m}_{F}^{\prime \prime}=0.02 \mathrm{~kg} / \mathrm{m}^{2}$ [7] for the mass pyrolysis rate at over-ventilated conditions. We also have taken the whole floor area $\left(4 \times 5=20 \mathrm{~m}^{2}\right)$ as the effective fuel area AF in Eq. (10). Using the so determined value of the length scale $\ell_{1}$ the maximum flame height and heat flux are determined from Eqs. (6a) and (7). Beyond these extreme values (continuous flame height $2.62 \mathrm{~m}$ for office and $4.05 \mathrm{~m}$ for shop, see Figs. 4 and 5) the fire in the enclosure becomes over ventilated and the extent of the flame height is minimal primarily determined by the ceiling area and length of the enclosure. Figs. 6 and 7 illustrate the crossover from under-ventilated to over-ventilated fires for the case of the office. The spandrel height can be determined for given opening dimensions in Figs. 4 and 5 using Eqs. (9a), (9b) and (9c). 


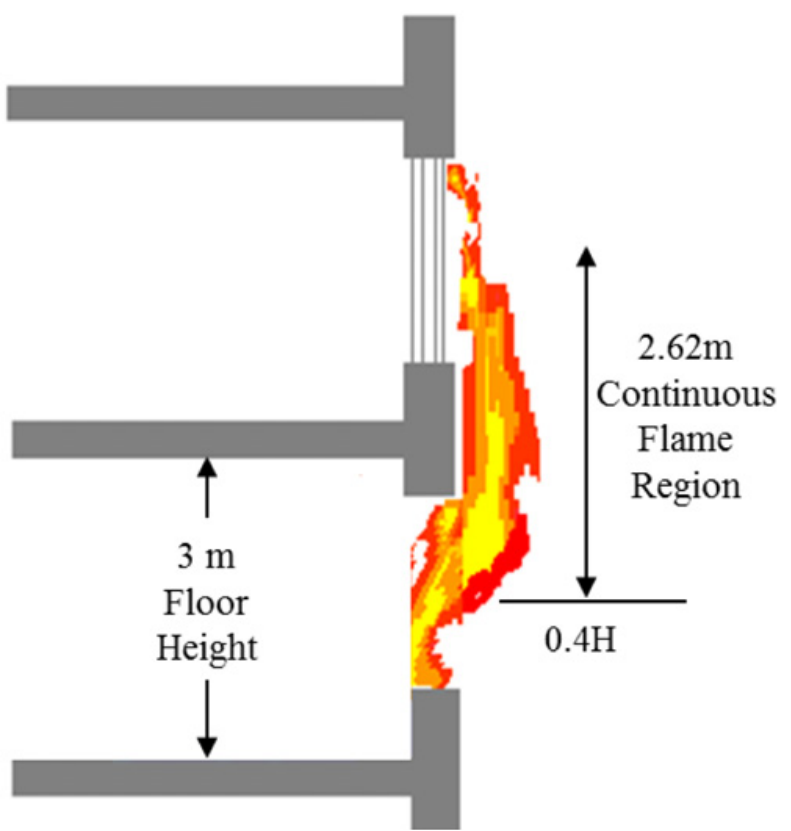

Figure 6. Office: $2.62 \mathrm{~m}$ Flame Height - Under-Ventilated Crossover Fire Measured from 0.4H Level.

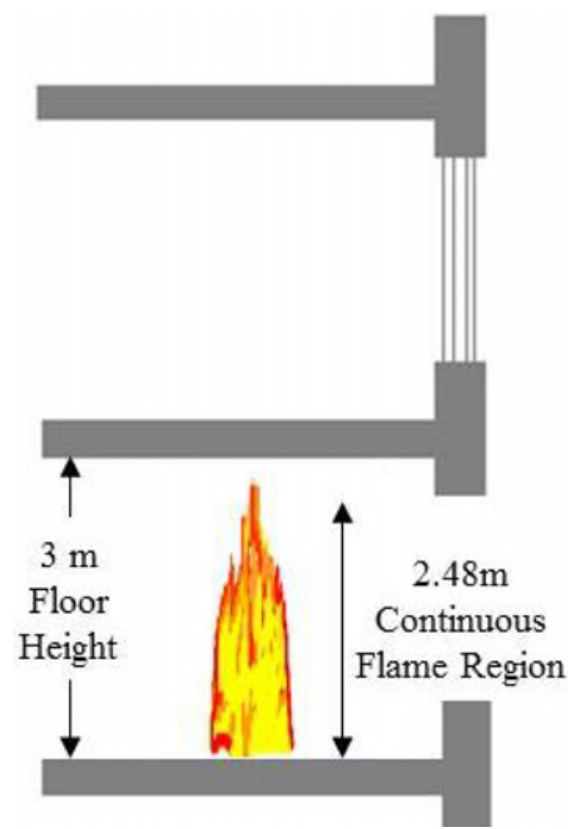

Figure 7. Office: Flame Height 2.48 m - Just Well-Ventilated Fire Calculation from Floor Level. 
$2^{\text {nd }}$ International Seminar for Fire Safety of Facades, Lund (Sweden), 2016

\section{CONCLUSIONS}

The major results of this work for specifying spandrel height to prevent façade fire spread from floor to floor through glazing (see Fig. 1) are applied in Figs. 4-7 and summarized as follows:

1. For given room and opening sizes and fuel type, the flame height and heat flux distributions are shown in Figs. 2 and 3 and calculated using Eqs. (6) and (8) for under ventilated conditions.

2. Glazing failure occurs when the façade flame heat flux is greater than a critical heat flux for glazing failure at the base of the opening at the floor above the floor of fire origin. The critical heat flux is taken to be $70 \mathrm{~kW} / \mathrm{m}^{2}$ for tempered glass and $20 \mathrm{~kW} / \mathrm{m}^{2}$ for normal glass.

3. The spandrel height to prevent fire spared is then determined using Eqs. (9a), (9b) and (9c).

4. As the opening size at the room of fire origin increases, the conditions cross over from under ventilated to over ventilated conditions (see Eq. (10)) thus reducing the façade fire spread hazard.

5. The results for flame height, heat flux distribution and cross over can also be applied to assess the façade fire spread hazard owing to other failure mechanisms listed at the beginning of the introduction including lightweight wall façades and wooden façades.

\section{References}

[1] Delichatsios, M.A., "Enclosure and Façade Fires: Physics and Applications", Fire Safety Science 11, 3-27, 2014.

[2] Lee, YP., Delichatsios, M.A., and Ohmiya, Y., "The Physics of the Outflow from the Opening of an Enclosure Fire and Re-examination of Yokoi's Correlation", Fire Safety Journal, 49, 82-88, 2013.

[3] Lee, YP., Delichatsios, M.A., Ohmiya, Y., Wakatsuki, K., Yanagisawa, A., and Goto, D., "Heat Fluxes on Opposite Building Wall by Flames Emerging from an Enclosure", Proceedings of the Combustion Institute, 32 (2), 2551-2558, 2009.

[4] Lee, YP., Delichatsios, M.A., and Silcock , G.W.H., "Heat Fluxes and Flame Heights in Façades from Fires in Enclosures of Varying Geometry", Proceedings of the Combustion Institute, 31 (2), 2521-2528, 2007.

[5] Lu, K., Hua, L., Delichatsios, M.A., Tang, F., Qiu, Z., and He, L., "Merging Behavior of Façade Flames Ejected from Two Windows of an Under-ventilated Compartment Fire", Proceedings of the Combustion Institute, 35 (3), 2615-2622, 2015.

[6] White, N., and Delichatsios, M.A, "Fire Hazards of Exterior Wall Assemblies Containing Combustible Components", Fire Protection Research Foundation, Document Number: EP142293, Quincy, Massachusetts, U.S.A, 2014.

[7] Quintiere, J.G., Principles of Fire Behaviour, Delmar Publishers, 1998.

[8] Drysdale, D., An Introduction to Fire Dynamics, John Wiley \& Sons, 1985.

[9] Steckler, K.D., Quintiere, J.G., and Rinkinen, W.J., "Flow Induced by a Fire in a Compartment", $19^{\text {th }}$ Symposium on Combustion, 913-920, Haifa, Israel, 8-13 August, 1982.

[10] Kawagoe, K., "Estimation of Fire Temperature-Time Curve in Rooms", Building Research Institute, Third Report BRI Research Paper No.29, Tokyo, Japan, 1967.

[11] "Application of Fire Safety Engineering Principles to the Design of Buildings - Initiation and Development of Fire within the Enclosure of Origin", PD 7974-1, British Standards Institute, 2003.

[12] Fire Engineering CIBSE Guide E, 2003.

[13] Babrauskas, V., "Glass Breakage in Fires", The Fire Place (Washington Chapter IAAI Newsletter), 15-18 (Feb/Mar 1998). Reprinted in: Hotline (Missouri Chapter IAAI Newsletter) 14, 18-21 (Summer 1998). 